Bajopas Volume 2 Number 2 December, 2009

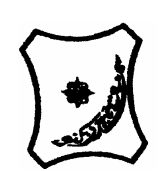

Bayero Journal of Pure and Applied Sciences, 2(2): 218 - 222

Received: Augustl, 2009

Accepted: November, 2009

\title{
A SURVEY OF SORGHUM DOWNY MILDEW IN SORGHUM IN THE SUDANO- SAHELIAN SAVANNA ZONES OF NIGERIA
}

\author{
*A.S. Kutama ${ }^{1}$, B.S. Aliyu ${ }^{1}$ and A.M.Emechebe ${ }^{2}$ \\ ${ }^{1}$ Department of Biological Sciences,Faculty of Sciences, Bayero University, Kano \\ ${ }^{2}$ Department of Agronomy, Faculty of Agriculture, Bayero University, Kano \\ *Correspondence author: kutamasak@yahoo.com
}

\begin{abstract}
An extensive survey was conducted across the 13 states constituting the Sudan and Sahel savanna agro-ecological zones of Nigeria to determine the occurrence and distribution of sorghum downy mildew in sorghum during the 2008 growing season. The survey was conducted at two different stages of the crop development; seedling and dough stage. The first survey was in early July while the second was carried out in late September. Three farmers' fields were critically investigated at every stop on a road system. During the first survey, a total of 97 farmers' fields in 36 locations were investigated while 110 sorghum fields in 37 locations were visited in the second survey. Average incidence (\%) of the disease was obtained from a sample of 100 plants selected using simple random sampling technique from each of the three farms visited per stop. Results of the survey (16.20 and 9.64\% and 3.28 and 1.16\% during the first and second visits in the Sudan and Sahel savanna AEZs respectively) indicated that the disease was present only at the seedling stage and virtually absent at flowering stage. In the areas where it was noticed at the juvenile stage the incidence was more prevalent in the Sudan than in the sahel savanna regions. The results also revealed that there was a relationship between soil type (which was mostly sandy loam) and disease incidence. Disease incidence was relatively higher on sandy loam soil than other soil types. The prevalence was generally low, but efforts should be made towards controlling the spread of the disease further. Farmers should be advised to use improved cultural practices like early sowing, seed dressing with the sole aim of reducing the disease.
\end{abstract}

Keywords: sorghum downy mildew, incidence, distribution, Sudan and Sahel savanna agroecological zones

\section{INTRODUCTION}

Sorghum Downy Mildew (SDM) induced by Peronosclerospora sorghi (Weston and Uppal) C.G.Shaw is a serious disease of sorghum and maize and causes heavy losses in the grain yield in many parts of the semi-arid tropics where sorghum is staple for human and other animal consumption (Kamala et al., 2002). The disease causes economically significant losses in sorghum production in many parts of the world (Jeger et al., 1998). In the southern guinea savanna of Nigeria, loss due to the disease in maize ranges between 40-100\% (Anaso et al., 1989). In northern Nigeria, sorghum downy mildew in sorghum was first reported in 1962 (Haris, 1962) and on maize in 1970 at Samaru (Kings and Webster, 1970). Jeger et al. (1998) demonstrated that the epidemics of $P$. sorghi in Africa appear to be more sporadic than $S$. graminicola causing downy mildew in pearl millet. Downy mildew is a systemic infection that affects both young and mature plants. Young plants may be infected through the shoots by conidia or through roots by soil infesting oospores (Bock, 1995). In regions with distinct dry season and no collateral host, the primary systemic infection will arise from soilborne oospores (Jeger et al., 1998).

The disease was observed on both sorghum and maize in the Guinea savanna and only on maize in the forest zone (Olanya et al., 1993). The disease in the southern part of Nigeria does not seem to infect sorghum even when susceptible varieties were exposed to P. sorghi (Anaso et al., 1989). Although the disease appeared to be more severe in maize than sorghum, pockets of its occurrence have been reported in the Sudan savanna agro- ecological zone (Selvaraj, 1979). Kutama et al. (2008) have observed a farmer's sorghum field with $>45 \%$ SDM infection in the Sudan savanna zone during the 2006 rain-fed season, although it might be an isolated case (Anaso pers. com.). Therefore, $P$. sorghi in sorghum can be found in the Sudan and Sahel (dry) savannah zones of northern Nigeria despite the erratic nature of rainfall and other environmental factors as well as the various practices employed. This may be true going by the report of Ikwele et al. (1990), and Zarafi and Emechebe (2005) that the occurrence and effect of downy mildew on yield of millet is influenced by genotype, aggressiveness of the pathogen and environmental conditions and or geographical locations since the two pathogens ( $S$. graminicola and $P$. sorghi) are very much similar in structure and epidemiological requirements (Tarr, 1962). This connotes that a resistant variety in one region may not be resistant in other geographical settings. 
In some areas and seasons, outbreaks of downy mildew of sorghum occurs but in others the disease is virtually absent or although severe on individual plant, does not appear to spread to any marked extent (Jeger et al.1998). However, there is paucity of information on the occurrence, distribution and severity of the disease SDM on sorghum in the Sudan and Sahel savanna zone of Nigeria where the bulk of the crop is produced. (Kutama et al., 2008). This study was aimed at providing baseline information on the occurrence and distribution of sorghum downy mildew in the Sudan and Sahel savanna zones of Nigeria.

\section{MATERIALS AND METHODS}

\section{Study Area}

The surveys covered the Sudan and Sahel savanna agro ecological- zones (AEZs) of Nigeria comprising of thirteen states where sorghum is grown in substantial quantity by peasant farmers. The states were Bauchi, Jigawa, Kano, Kaduna, Katsina, Kebbi, Gombe, Taraba, Adamawa, Yobe, Sokoto and Zamfara states belonging to Sudan savanna and Borno state belonging to the Sahel savanna AEZs (Figure 1.).

Total number of diseased plants $\mathrm{X} 100$

Incidence $=$

$$
\text { Number of plants examined }
$$

The same farmers' fields were visited in the first and second surveys. Other important parameters recorded during the survey were size of the farm, sorghum variety, soil type, manually determined by squeezing a sample of soil from each field visited, stage of plant development, agronomic status of the farm (whether weeded or weedy, fertilized or not, sole cropped or intercropped), the presence or absence of other diseases or pest attack, and the economic status of the farmers.

\section{Field Surveys}

Fields surveys were conducted twice during the 2008 rain-fed season. The first survey was conducted in July when most plants were at seedling stage or when most plants were at 1-5 leaves growth stage (Bigirwa et al., 1998). The second survey was conducted at dough stage in late September, when most of the sorghum plants were about to flower or at flowering stage (Ritchie et al., 1989; Bigirwa et al., 1998). During the study, farmers' fields were surveyed every $30-35 \mathrm{~km}$ along accessible roads. At each location or stop, at least three sorghum farms/ fields were inspected, each field serving as a replication. Symptoms (local and systemic) were critically observed from a random sample of 100 plants in each field and the incidence was obtained by adding up the number of symptomatic plants (local and systemic) observed and expressing this as a percentage of total number of plant examined as demonstrated by James (1974 ) and Chaube and Punder (2005) using the formula;

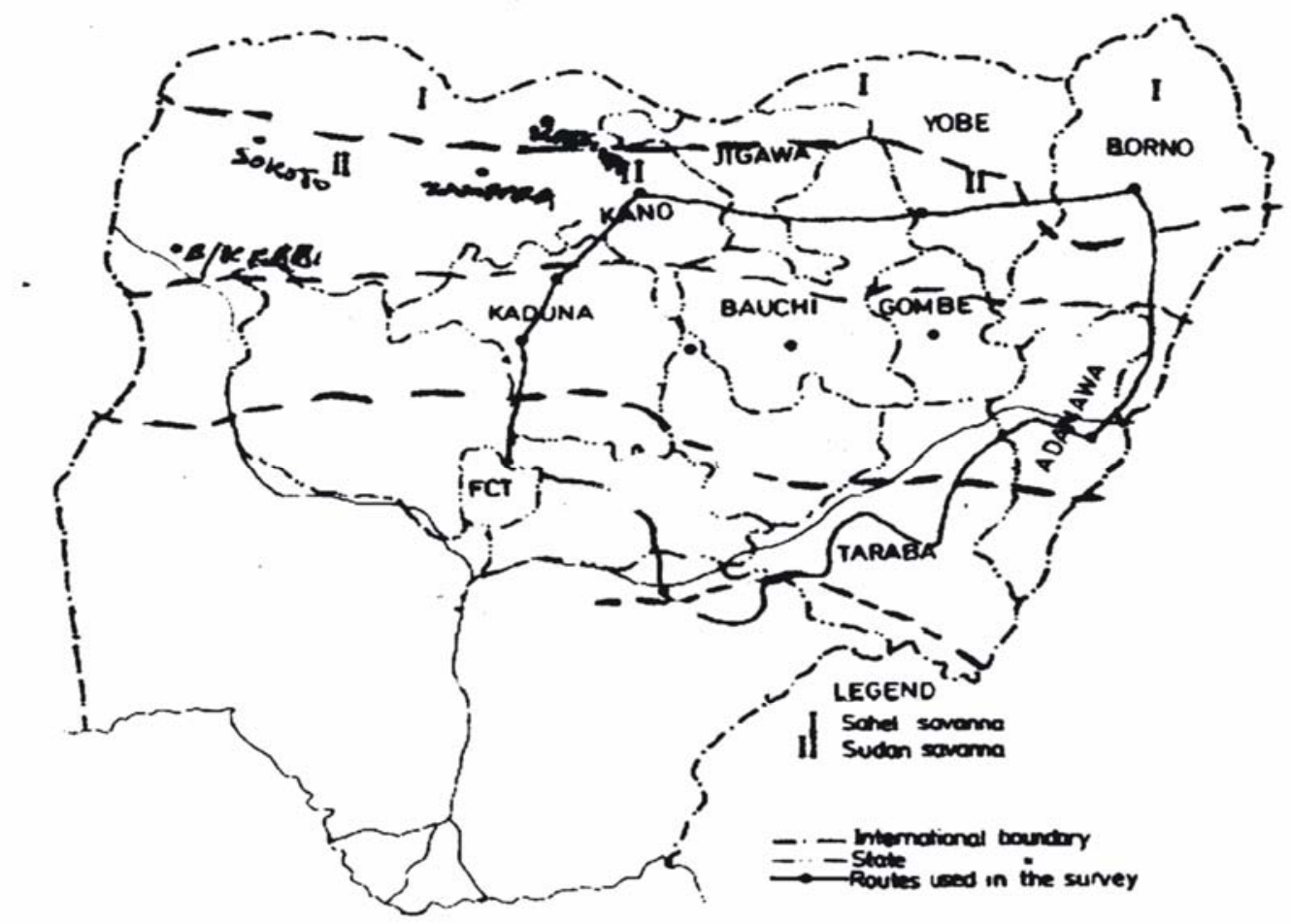

Figure1: Map of Nigeria showing the areas visited during the survey in 2008 
Bajopas Volume 2 Number 2 December, 2009

\section{RESULTS AND DISCUSSION}

\section{Occurrence and distribution of SDM}

Downy mildew symptoms in sorghum were observed in some of the farmers' fields surveyed. Local infection symptoms were observed during the first survey, when most plants were at seedling stage. Out of the 36 locations surveyed, 19 locations had infected plants (Table 1) showing chlorosis of leaves, usually resulting from seedling infection by soil-borne oospores. Major symptoms of SDM infection on sorghum at seedling stage was observed in Bauchi, Gombe and Adamawa states. Quite numbers of the infected plants were also recorded in Kano, Borno and Katsina states (Table 2). There was a significant $(P>0.05)$ difference in SDM infection between the different locations with SDM infection on sorghum.

Results for the second visit showed that of the 13 states, the disease was noticed in only two states; Gombe and Adamawa states (Table 2). The symptoms observed during the second survey included stunting, irregular striping of leaves, absence of panicle or panicles without grains, but without shredding and oospores production which is virtually unusual with SDM symptoms in sorghum. The overall prevalence of the disease was generally low ( 16.20 and $9.64 \%$ and 3.28 and $1.16 \%$ during the first and second visits in the Sudan and Sahel savanna AEZs respectively) even in areas with the initial symptom (Table 2). This suggests that the disease is of low economic importance as reported by Bigirwa et al. (1998) in Kenya. However, the presence of the disease at seedling stage could be a Ipotential danger to sorghum production in this part of the country in the future once epidemic conditions prevail.

There was significant $(P>0.05)$ difference in the occurrence of the disease in the first and second surveys (Table 1). These wide differences in the disease incidence might be due to variation in inoculum dosage and escape from infection or recovery from symptoms as was suggested for SDM in maize by Olanya and Fajemisin (1992). Studies on symptom remission have shown that infected maize genotypes recover from downy mildew infection produced normal cobs or ears (Olanya and Fajemisin ,1992).

Soil Type, Sorghum Variety and Agronomic Status

The results of the survey have shown that sorghum is grown on sandy loam soils in most $(>85 \%)$ of the agricultural fields investigated (Table 3 ) and that it was on very few of the farms that sorghum is cultivated on clay-loam /clay soils. There seemed to be a relationship and or trend between the soil type and the incidence of SDM at seedling stage. Soil type has significant effect on the incidence of sorghum downy mildew in Kenya (Bigirwa et al., 1998) but the reason for this may be obscure. Although most reports gave inconclusive and contradictory information of the effect of nutrition on the incidence of SDM in sorghum, it appears that nitrogen and phosphorus may reduce the incidence of SDM (Williams, 1984). Bonman and Pittiporuchori (1984) found that early planted maize crops in Thailand had reduced levels of maize downy mildew when nitrogen or nitrogen plus phosphorus was applied. This might be true since clay soil contains more of these nutrients (Aliyu and Kutama, 2007).

The results of the survey also indicated that in virtually all the sorghum farms visited in both the Sudan and Sahel savanna zones, $2 \%$ of the total sorghum varieties /lines grown were improved varieties. $98 \%$ were local varieties which could be categorized into; Kaura (yellow/red), Farfara, Yalai and Basharamba. These varieties were grown using different cropping systems. Results of this survey have shown that $53 \%$ of the sorghum fields visited had sorghum planted as a sole crop (Table 3). Hoever. In about $47 \%$ of the fields visited, it was observed that sorghum in the two agro ecological zones was intercropped with cowpea, maize, millet, or soybean. This agrees with the report of Zarafi and Emechebe (2005) on pearl millet in Nigeria. Cropping pattern seemed to have a relation with the occurrence and distribution of the disease in the study area. These results, however, do not conform to the results obtained by Olanya et al. (1993) on maize who suggested that cropping system did not have any significant effect on the incidence of downy mildew in maize.

\section{Conclusion}

The incidence and distribution of Sorghum downy mildew was generally low in sorghum in the two AEZs but was relatively higher at the seedling stage than at later growing stage and in the Sudan savanna than Sahel savanna zones. Although the occurrence is not of a serious magnitude, there is still need to control the situation to avoid what happened in the forest and southern guinea savanna on maize in the 1990s would not be repeated. "Prevention, they say, is always better than cure"

Table 1: Number of locations with SDM symptoms in the Sudan and Sahel savanna AEZs during the 2008 growing season

\begin{tabular}{lcccc}
\hline AEZ & First visit & Number of Locations with SDM & Second visit & Number of Locations with SDM \\
\hline Sudan & 15 & 8 & 18 & 2 \\
Sahel & 17 & 2 & 18 & 0.0 \\
Total & $\mathbf{3 2}$ & $\mathbf{1 0}$ & $\mathbf{3 6}$ & $\mathbf{2}$ \\
\hline
\end{tabular}

$(p>0.05)$


Bajopas Volume 2 Number 2 December, 2009

Table 2: Occurrence (\%) of SDM in Sorghum in the states constituting the Sudan and Sahel savanna AEZs. During the $\mathbf{2 0 0 8}$ growing season

\begin{tabular}{lcc}
\hline & \multicolumn{1}{c}{ Incidence of SDM } & \\
State & First visit $^{\mathrm{a}}$ & Second visit $^{\mathrm{b}}$ \\
\hline Adamawa & 18.2 & 7.3 \\
Sokoto & 0.0 & 0.0 \\
Kano & 2.0 & 0.0 \\
Gombe & 11.2 & 6.0 \\
Taraba & 0.5 & 0.0 \\
Zamfara & 0.0 & 0.0 \\
Katsina & 3.8 & 0.0 \\
Yobe & 0.4 & 0.0 \\
Borno & 6.9 & 0.2 \\
Jigawa & 1.6 & 0.0 \\
Kebbi & 0.0 & 0.0 \\
Kaduna & 0.0 & 0.0 \\
Bauchi & 12.2 & 0.0 \\
\hline :First visit was don
\end{tabular}

$\mathrm{a}$ :First visit was done in July,2008

$\mathrm{b}$ :Second visit was conducted in September,2008.

Table 3: Soil type, sorghum variety and the agronomic status of locations surveyed for SDM in sorghum in the 2008 growing season.

\begin{tabular}{|c|c|c|c|}
\hline Location & Soil type & Sorghum variety grown & Agronomic status \\
\hline Makole & sandy loam & Local & sole cropped \\
\hline $\mathrm{K} /$ Huguma & sandy loam & Local & ercropped with maize \\
\hline K/babaldo & sandy loam & Local & e cropped \\
\hline Ningi & sandy loam & Local & mixed with maize \&cowpea \\
\hline Alkaleri & sandy loam & Local & nter cropped with soybean \& millet \\
\hline Bauchi & sandy loam & Local & ntercropped with sorghum \&cowpea \\
\hline Ganjuwa & sandy loam & Local & inter cropped with sorghum \\
\hline Durun & sandy loam & Local & sole cropped \\
\hline Natsira & sandy loam & Local & sole cropped \\
\hline Gombe & sandy loam & Local & inter cropped with cowpea \\
\hline Dadin kowa & clay loam & Local & ole cropped \\
\hline Kwaya kusar & sandy loam & Local & sole cropped \\
\hline Biu & sandy loam & Local & sole cropped \\
\hline Hawul & sandy loam & Local & sole cropped \\
\hline Garkida & clay loam & Local & sole cropped \\
\hline Damaturu & sandy loam & Local & sole cropped \\
\hline Gujba & sandy loam & Local & sole cropped \\
\hline Gumbi & clay loam & Local & sole cropped \\
\hline Song & sandy loam & Local & sole crop \\
\hline Murke & sandy loam & Local & sole cropped \\
\hline Yola south & sandy loam & Local & inter cropped with soybean \\
\hline Demsa/Numan & sandy loam & Local & sole crop \\
\hline Ungogo & sandy loam & Local & inter cropped with maize \\
\hline Kanye & sandy loam & inter c & cropped with millet and cowpea \\
\hline Dayi & sandy loam & Local & er cropped with millet \\
\hline K/Kankara & sandy loam & Local & le crop \\
\hline Faskari & sandy loam & Improved & ercropped with maize \\
\hline Tsafe & sandy loam & Local & sole cropped \\
\hline Kwatarkwashi & sandy loam & improved & sole cropped \\
\hline Maru & sandy loam & Local & inter cropped with millet \\
\hline Danbaza & sandy loam & Local & sole cropped \\
\hline Lambar bakura & sandy loam & Local & inter cropped with cowpea \\
\hline Sabon birni & sandy loam & Local & sole cropped \\
\hline Dange-Shuni & sandy loam & Local & intercropped with millet \\
\hline Sokoto south & sandy loam & Local & inter cropped with cowpea \\
\hline Gwandu & sandy loam & Local & sole cropped \\
\hline
\end{tabular}


Bajopas Volume 2 Number 2 December, 2009

Acknowledgements

The authors are indebted to Mallam Musa Muhammad Kutama and Mallam Abdullahi Muhammad Adamu for their kind gestures during the surveys. May God bless them and their families, amin.

\section{REFERENCES}

Aliyu, B.S. and Kutama, A.S.(2007) Assessing the Potentials of Growing SAMCOT 9 Cotton Variety in Kano and Katsina states. Science World Journal.1 (2):32-36

Anaso, A. B., Emechebe, A.B.,Tyagi,P.D. and Manzo,S.K.(1989) Assessment of loss in yield due to sorghum downy mildew ( $P$. sorghi) of maize in Nigeria guinea savanna.Trop.Pest management 30:301-303

Bigirwa, G., E. Adipala, J.P.Esele (1998) Occurrence of Peronosclerospora sorghi in Uganda. Plant Disease, 82 (7):757-760

Bock, C.H. (1995) Studies of the Epidemiology, Variability and Control of Sorghum Downy Mildew (P.Sorghi) (Weston and Uppal) C.G.Shaw, On Sorghum In Africa. Reading U.K. University of Reading. Department Of Agriculture.Ph.D Theses

Bonman, J.M. andPittiporuchai, P.(1984) Effect of fertilizer and plant age on downy mildew of maize. Journal of Plant Protection in the Tropics.1:59-61

Chaube,H.S.,Punder,V.S. Crop Diseases and their Management. Oxford and IBH Publishing Co. PVT.LTD pp23-56

Harris,E.(1962) Diseases Of Guinea corn. Samaru Technical Notes, Volume II. Zaria, Nigeria: Institute of Agricultural Research

Ikwele, M.C., D.A.Labe, and C.C.Nwasike (1990) Millet production in Nigeria: constraints and prospects.pp122-129 In: O.Youm and K.A.Kumar(Eds.). Proceedings of Regional Pearl Millet Workshop. International Crop Research Institute for the Semi Arid Tropics (ICRISAT) Sahelian center, Niamey, Niger.

James,W.C.(1974) Assessment of Plant Diseases and Losses. Ann.Rev.Phytophythology 12:27-48

Jeger,M.J.,Gilijamse,E.,Bock,C.H.,Frinking,H.D.(1998) The Epidemiology, Variability And Control Of The Downy Mildews Of Pearl Millet And Sorghum With Particular References To Africa. Plant Pathology, 47:544-569

Kamala, V.,Singh,S.D.Bramel,P.J. and Manohar Rao,D.(2002) Sources of resistance to sorghum downy mildew in wild and weedy sorghums. Crop science 42:1357-1360

Kings, S.B. And Webster, O.J.(1970) Downy Mildew Of Sorghum In Nigeria. Indian Phytopathology 23:342-349

Kutama, A.S., B.S.Aliyu, Nuraddin, A. and S.A.Kiyawa (2008) Green House Evaluation of the Epidemiology of Sorghum Downy Mildew in Some Varieties of Sorghum and Their Chemical Control. In The Proceedings of International Conference on Research and Development Vol.1 No.13, November 2528.Institute of African Studies,
University Of Ghana, Accra, Ghana. Pp. 6367

Olanya, O.M., and Fajemisin, J.M.(1992) Remission of symptoms of downy mildew disease on maize in northern Nigeria. Plant disease.76:753

Olanya, O.M. and Fajemisin, J.M.(1993) Host Range and survival studies of $\mathrm{P}$. sorghi at different locations in Nigeria. International journal of pest management 39:13-18

Olanya,O.M.,Fajemisin,J.M.,Oyekan,P.(1993) Incidence And Geographical Distribution Of Maize Downy Mildew Caused By P. sorghi In Nigeria. International Journal of Pest Management, 39:28-34

Ritchie, W., Hanway, J.J. And Abaenson, G.O.(1989) How A Corn Plant Develops. Special Report.No.48.Iowa State University, Ames.

Selvaraj D.S. (1979) Cultural practices to decrease losses due to corn Downy Midew. Tropical Agricultural Research series 8:165-175

Tarr, S.A.J.(1962) Diseases of Sorghum, Sudan grass and Broom corn. Kew, Surrey, England: Common Wealth Mycological Institute. 380pp

Williams,R.J.(1984) Downy Mildew of tropical cereals. Advances in plant Pathology 3:1-103.

Zarafi, A.B., A.M. Emechebe (2005)Incidence of pearl millet downy mildew (Sclerospora graminicola(Sacc)] in Nigeria. Journal of plant protection research, 45(3):155-162. 